\title{
Ethics of emergent information and communication technology applications in humanitarian medical assistance
}

\author{
Matthew Hunt ${ }^{a, *}$, John Pringle ${ }^{b}$, Markus Christen $^{c}$, Lisa Eckenwiler ${ }^{d}$, Lisa Schwartz ${ }^{e}$ and Anushree Davéf \\ ${ }^{a}$ School of Physical and Occupational Therapy, McGill University, and Centre for Interdisciplinary Research on Rehabilitation, 3654 Prom \\ Sir William Osler, Montreal, H3G 1Y5, Quebec, Canada; ' ${ }^{b}$ umanitarian Health Ethics Research Group, McGill University, 3640 Rue de la \\ Montagne, Montreal, H3G 2A8, Quebec, Canada; 'Center for Ethics, University of Zurich, Zollikerstrasse 117, Zurich, CH-8008, \\ Switzerland; ${ }^{d}$ Departments of Philosophy and Health Policy, George Mason University, 4400 University Drive, Fairfax, VA, 22030, USA; \\ ${ }^{e}$ Department of Clinical Epidemiology \& Biostatistics, McMaster University, 1280 Main Street W, Hamilton, L8S 4K1, Ontario, Canada; \\ fBiomedical Ethics Unit, 3647 Peel St, McGill University, Montreal, H3A 1X1, Quebec, Canada \\ *Corresponding author: Tel: +1 5143984400 00289; E-mail: matthew.hunt@mcgill.ca
}

Received 18 March 2016; revised 12 May 2016; accepted 13 May 2016

\begin{abstract}
New applications of information and communication technology (ICT) are shaping the way we understand and provide humanitarian medical assistance in situations of disaster, disease outbreak or conflict. Each new crisis appears to be accompanied by advancements in humanitarian technology, leading to significant improvements in the humanitarian aid sector. However, ICTs raise ethical questions that warrant attention. Focusing on the context of humanitarian medical assistance, we review key domains of ICT innovation. We then discuss ethical challenges and uncertainties associated with the development and application of new ICTs in humanitarian medical assistance, including ensuring accuracy, protecting privacy and security, responding to inequalities, demonstrating respect, protecting relationships, and addressing expectations. In doing so, we emphasize the centrality of ethics in humanitarian ICT design, application and evaluation.
\end{abstract}

Keywords: Digital, Disasters, Ethics, Humanitarian aid, Information and communication technology, Innovation

\section{Introduction}

At the 2015 Annual General Meeting of Médecins Sans Frontières (MSF) Canada, an unmanned aerial vehicle (UAV) hovered over attendees before flying high into the distance. Those who lost sight of it watched its live camera feed on a handheld monitor. Within the hour, computer software was generating a 3D map of the local area. The dramatic demonstration both impressed attendees and illustrated the potential for UAVs in humanitarian medical assistance. One could be excused for mistaking this humanitarian agency meeting for a technology convention; increasingly they are combined. ${ }^{1}$

New applications of information and communication technology (ICT) are having a profound effect on humanitarian assistance, 2,3 as 'every new emergency seems to trigger some new innovation'. 4, p.1 For example, networks of volunteers compiled text messages from people trapped or injured during the 2010 Haiti earthquake to create a live crowd-sourced map of the disaster area that was then used by first responders to guide rescue efforts, and new smartphone apps were developed to facilitate communication between health workers during the
2014 West Africa Ebola crisis. ${ }^{5,6}$ Humanitarian ICTs-that is, ICT applications used to support relief and reconstruction efforts during the international response to disaster, war or disease outbreak-are thus a quickly evolving domain.

The implementation of novel technologies is often associated with both enthusiasm and trepidation, and the context of humanitarian medical assistance is no exception. Those who are techno-optimists may laud positive aspects of new technologies such as increased efficiency, ease of data sharing and diminished risks for aid workers. Techno-pessimists may dwell on the inevitability of glitches in the field, over-reliance on electrical energy and internet access, and threats to data security or privacy. However, most aid workers are probably somewhere in between, enthusiastic about new possibilities but cautious about their implementation. They also realize that ICTs are becoming increasingly adapted to field conditions due to advances in battery technology, and more widespread cellular phone networks. ${ }^{7}$ Indeed, many technologies that were recently considered novel are now viewed as standard and routine, such as obtaining internet access over cellular and satellite networks. These advances are expanding the scope and extending 
the reach of ICT use across the humanitarian aid sector, and the rate of new technology application is likely to accelerate, making the need for ethical scrutiny that much more pressing.

While new ICT unveilings garner close attention and exploration, including by industry and entrepreneurs, it is important to carefully consider ethical ramifications of ICT application in humanitarian medical assistance. In this paper we survey key domains of emergent humanitarian ICTs and discuss the ethical challenges and uncertainties associated with their development for and application in humanitarian medical assistance. In so doing, we underscore the importance of ethical scrutiny in not just the application of humanitarian technologies, but also their design and the initial consideration of their use.

\section{ICTs in humanitarian medical assistance}

ICTs have a range of applications for humanitarian medical assistance:

1. Maps: Maps are being created using satellite and UAV imagery, geographic information systems (GIS) and social media information gathered by networks of volunteers. As a result, epidemiological and humanitarian maps have shifted from static geographic representations to include near realtime information, such as locations and narratives of events, and can be used to track trends such as population displacement or disease spread. ${ }^{8,9}$ Mapping technologies can also facilitate the identification and tracking of individuals, such as family members, who may be on the move following a disaster. ${ }^{10}$

2. Remote visualization and surveillance: Remote visualization and surveillance are also facilitated by a range of ICTs. UAVs ${ }^{11}$ and satellites are used to identify populations fleeing conflict or disaster. Closed-circuit video feeds were also used to monitor patients in Ebola treatment centers to reduce the number of health providers who needed to remain in the isolation unit.

3. Point of care testing: Point of care testing encompasses portable, self-contained devices for disease screening and diagnostic testing. These technologies are especially valuable during humanitarian crises (e.g., www.elrha.org/news/elrhafunds-new-15-minute-test-ebola-trialled-guinea-2/) where access to laboratory facilities is limited or impossible.

4. Early warning technologies: Early warning technologies for disasters, political instability, and epidemics are becoming increasing powerful. Sophisticated computer algorithms are used to analyze social media data and identify the onset or track the spread of a crisis, ${ }^{12,13}$ along with networks of sensors that are deployed to detect tsunamis and other hazards. ${ }^{14}$

5. Information sharing and evaluation: Information sharing and evaluation are aided by text messages and diverse social media platforms. Such information may be directed toward the population, (e.g., automatic text messages sent to the cell phones of all individuals entering an area affected by cholera) or as a channel for local communities to provide feedback to aid organizations. ${ }^{15}$ Increased two-way communication between communities and humanitarian agencies enhances accountability and can facilitate responsiveness to local needs. Family reunification efforts following a crisis are also increasingly carried out online, often replacing the use of posters covered with photos of individuals who were separated from other family members.

6. Coordination and data sharing: Coordination and data sharing between humanitarian agencies has been criticized as inadequate and resulting in diminished effectiveness of aid efforts. ${ }^{16}$ ICTs, including smartphone apps and text messaging, can be harnessed to enhance coordination within and between aid agencies in an effort to reduce duplication and gaps in the provision of assistance. ${ }^{17,18}$

7. Digital data collection: Digital data collection in humanitarian medical assistance is rapidly expanding, including incorporation of digital patient records in field hospitals. ${ }^{19}$

8. Tele-consulting: Tele-consulting (telemedicine or electronic consultation) has been refined over the past decade in diverse humanitarian crises..$^{20,21}$ From simple cell-phone consultations, to a physician wearing a camera integrated into their eye glasses during triage, ${ }^{22}$ ICTs provide opportunities for clinicians to consult distant colleagues during crises.

9. Simulations and predictive modeling: Simulations and predictive modeling using virtual reality technology replicate field situations and can be incorporated in staff selection and training, preparation of field missions, and in advocacy efforts. ${ }^{23}$ Virtual reality technology may in future also become tools for decision support and predictive modeling.

These categories reflect important areas of ICT application by medical humanitarian organizations. There are also numerous other ICT uses in the humanitarian aid sector ranging from supply chain management, ${ }^{24}$ to electronic cash transfers to refugees, ${ }^{2}$ to broader analyses of conflict or disaster patterns. ${ }^{25} \mathrm{New}$ humanitarian technologies continue to be developed and implemented by humanitarian agencies. Biometrics, such as voice recognition or retina scans used to restore lost documentation of refugees, and wearable devices to aid rescue efforts are two examples of cutting-edge technologies. ${ }^{3,26}$ New technology applications such as UAV delivery of relief equipment and onsite 3D printing of specialized supplies are also being trialed. ${ }^{27,28}$

\section{Uncertainty and challenges through an ethics lens}

Along with the great benefits of ICTs come uncertainties and challenges. ${ }^{29}$ While some challenges are logistical, such as issues of reliability and power requirements for ICTs in austere environments, ${ }^{30}$ other challenges relate to the values that ground humanitarianism and the ethical identities of humanitarian organizations and aid workers. Drawing on a review of the humanitarian and technology ethics literatures, as well as our experiences in the humanitarian aid sector, we identify and discuss six key ethical issues for ICT use by humanitarian medical organizations and consider how these issues relate to humanitarians' ethical commitments, such as the humanitarian principles of independence, impartiality, neutrality.

\section{Ensuring accuracy}

Effective decision-making by humanitarian organizations requires access to and rapid analysis of information about how 
a crisis is unfolding. ICT applications are crucial means of collecting this information, and are increasingly generating and using 'big data', which is broadly defined as the storage and analysis of large and/or complex data sets using sophisticated computing technology. ${ }^{31}$ Challenges arise to ensure that this real-time humanitarian decision-making is based on reliable information rather than information that is faulty or fraudulent. Inaccurate information or even deception (especially in contexts of civil war or political unrest) may lead to operational responses based on poor data, and thus may 'distort reality in a way that may invoke harm'. ${ }^{32}$ In some settings, misinformation or deception could also be used to misappropriate or disrupt assistance. ${ }^{5}$ Ensuring veracity and accuracy of ICT data is thus a crucial step to minimize the risk of harm and to support robust policy and operational decision-making.

\section{Protecting privacy and security}

Information collected by humanitarian aid organizations might also raise security risks if it is used by aggressors to target individuals or communities (e.g., for reprisals against those sharing information). Geopositioning raises 'ethical considerations of linking people to place, ${ }^{33}$ and may heighten vulnerability if ICTgenerated information contributes to or facilitates individuals being stigmatized or targeted, ${ }^{34}$ especially if data is traceable. Other risks may be linked to ICT use. In some instances, individuals may send sensitive information to humanitarian organizations through open channels (e.g., Twitter and website comment forums) without realizing the security risk. Debate is also ongoing about whether and when crisis maps should be open source and shared freely to promote rapid and well-informed decisionmaking, or encrypted and access controlled to minimize security risks. ${ }^{5}$ Data may still be vulnerable to theft or even subject to surveillance from state authorities or other entities, potentially undermining humanitarian neutrality and jeopardizing aid projects in some areas and placing individuals at risk. ${ }^{35-37}$ Furthermore, insider threats, where insiders (e.g., system administrators) take advantage of their position to bypass security measures, are considered one of the most powerful adversaries in ICT security generally; humanitarian aid organizations dealing with sensitive information should not ignore such concerns. ${ }^{38}$ Establishing and following rigorous ICT security practices is thus an increasingly important task for humanitarian organizations.

Even in non-conflict settings, collected information could lead to harm. ${ }^{39}$ For example, contact tracing maps of stigmatized infectious diseases (e.g., sexually transmitted infections and Ebola virus disease) could compromise anonymity and expose individuals to harm. Maps may also contain operational information such as identifying a village considered unresponsive or hostile by humanitarian workers, which might have negative consequences such as collective punishment from authorities.

\section{Responding to inequality}

Humanitarian ethics has long stressed the importance of fairness, including the equitable distribution of humanitarian aid. However, reliance on ICTs in humanitarian aid programs may exacerbate inequity. Though mobile technology is increasingly widespread around the world, access is not uniform due to service availability and costs. Poor or socially marginalized individuals are less likely to have access to critical information stemming from text messages and social media. ${ }^{40}$ In turn, operational decisions based on information received by means of these ICTs are less likely to be responsive to the needs of the most vulnerable persons in a community. ${ }^{30}$

\section{Demonstrating respect for individuals and communities}

As video and photography are used in advocacy, fundraising and awareness-raising, concerns about harm and exploitation associated with images of suffering in humanitarianism are relevant. ${ }^{41}$ ICTs are used to both gather and distribute these images. While concerns about imagery are not unique to humanitarian aid, they are amplified due to the insecurity and heightened vulnerability experienced by individuals and communities during crises. Digital data collection also raises questions about informed consent and ownership of information, including whether individuals know and accept the purposes for which their information will be used and how it will be stored. ${ }^{42}$ For example, publishing high resolution photography taken by UAVs without obtaining permission of identifiable individuals breaches privacy expectations and may threaten self determination and agency for individuals and groups, and thus constitute a harm to dignity. By extension, duties may exist to engage in community consultation for mapping, UAV or satellite photography activities after a disaster or during an outbreak. Such discussion should include consideration for ownership of the resulting maps or images, and the roles communities will play in deciding what uses are possible once the emergency abates.

\section{Protecting relationships}

ICTs can alter relationships between humanitarian actors and populations. They may facilitate a move from 'face-to-face' to 'face-to-screen' interactions, ${ }^{34}$ potentially undercutting the principle of proximity that is a core tenet of organizations such as MSF. ${ }^{43}$ As more humanitarian aid projects are run at a distance, there are situations characterized as the 'paradox of presence', where aid workers are present but spend much more time on their laptops than working directly with the population. ${ }^{44}$ While perhaps making operations more feasible in some locales, technological distancing may diminish connection and the experience of solidarity for both humanitarian workers and communities that receive assistance.

The use of ICTs may also have implications for how humanitarian actors are seen by local communities, including perceptions related to trust and neutrality. Some populations may confuse humanitarian technologies with military or state surveillance (consider a humanitarian aid agency launching a UAV from their compound in a setting where counter-terrorism activities are underway) thus undermining trust in humanitarian workers, and potentially fueling anxiety and jeopardizing aid worker security. The widespread use of remote imaging might 
M. Hunt et al.

also jeopardize local relationships in areas where photography is culturally sensitive and its use guided by cultural norms.

\section{Addressing expectations that cannot be met}

A final concern relates to the creation of expectations that humanitarian organizations are unable to meet. Increased twoway communication between humanitarians and affected populations via ICTs 'creates a different dynamic around accountability and responsiveness. It also creates a new set of ethical responsibilities, especially around (heightened) expectations and whether they can be met'. ${ }^{45}$ Technology-facilitated communication channels between aid agencies and local communities run both ways. While aid agencies may use the channels to raise awareness about their presence and their projects, local communities may seize the opportunity to convey additional needs and requests. In some instances, the possibility to voice needs may give rise to frustrations when they remain unmet by aid organizations who are overstretched or unable to respond. ${ }^{15}$ Thus while technology can enhance accountability and responsiveness, consideration should also be given to the ways that it contributes to raising expectations and how best to address them.

\section{What lies ahead for ethics and ICT development and application for humanitarian medical assistance?}

The pace of ICT innovation is rapid. As new ICTs are developed and implemented, humanitarian organizations and their partners should pursue three lines of questioning. The first line of questioning investigates how ICTs interact with the ethical values and norms of humanitarian organizations and aid workers. In the context of humanitarian medical assistance, these values include normative commitments to the fundamental humanitarian principles of impartiality, independence and neutrality, as well as concerns for upholding values such as fairness, solidarity, avoiding harm, and treating individuals and communities with respect. Ethical analysis of novel ICTs should also consider norms of distributive justice and equality. As noted earlier, ICTs may lead to (or reinforce) inequality due to differential access to technologies between those who are socially advantaged and those who are not. ${ }^{46}$ For example, a statement on best practices for humanitarian UAV missions rightly encourages UAV operators to avoid inadvertent discrimination by neglecting marginalized communities in their humanitarian efforts. ${ }^{47}$ Humanitarian organizations will also need to understand the regulatory context in which they operate, including expectations for notification of authorities related to the use of UAVs and privacy regulations related to the use and control of personal data. Following the notion of value-sensitive design, ${ }^{48}$ the development of new technologies should include reflection and analysis of how novel ICTs ought to be developed and implemented so as to uphold and sustain ethical commitments of humanitarian workers and humanitarian agencies. In this sense, congruence with ethical values is not merely a question that arises when decisions are made about technology application. Congruence with ethical values should also be examined in the development of new ICTs with humanitarian applications, especially given the potential harms associated with unintended effects, or that unscrupulous individuals might seek to subvert ICTs once they are implemented. ${ }^{49}$

Humanitarian medical organizations should also pursue a second line of questioning and examine how ICTs influence relationships in humanitarian aid. ICTs that facilitate remote operations, tele-consulting and new accountability mechanisms, may alter relationships between humanitarian workers, their patients, and others in affected communities. These alterations may affect the encounters that are central to humanitarian medical assistance. ${ }^{50}$ As ICTs mediate relationships in humanitarian aid, attention can be given to additional ethical considerations such as presence and responsiveness. ${ }^{51}$ ICTs are also leading to the creation of new relationships. New groups have joined humanitarian efforts requiring partnerships between professionalized humanitarian agencies and volunteer-based online networks (sometimes referred to as 'digital humanitarians'). ${ }^{5}$ With new partnerships arise new tensions resulting from the different standards, identities, and expectations of these groups. Tensions may also occur between technology companies' duties to their shareholders and the obligations and commitments of medical humanitarian organizations. ${ }^{29}$ Humanitarian organizations also rely on third party technology service providers, raising questions related to control over data, and ensuring that expectations and service agreements are clear and harmonized with humanitarian objectives. Concerns may also arise related to continuity of services if a humanitarian agency partners with a firm that subsequently ceases to function. While these are sources of concern, it remains to be seen if developments in open-source technology will reduce the need for humanitarian organizations to partner with for-profit corporations. More challenging yet for humanitarian public perception is dual-use technology: many ICTs designed for military use also have humanitarian applications. Potential cross purposing of technologies for military and humanitarian application should be carefully evaluated and transparently disclosed, including the role of defense contractors in humanitarian technology development.

The final line of questioning responds to the observation that technology deployment cannot necessarily be undone - and that those who did not consent or were not informed will still be affected by these changes. ${ }^{52}$ Prior to developing or implementing new ICTs, humanitarian agencies should carefully assess potential consequences and the possibility of mitigating unintended harms. For example, where a live map that includes information about those who were injured during demonstrations has been made freely available online, this information cannot be effectively removed if it is later revealed that it is being used as a tool of oppression by state authorities or counter-demonstrators. Anticipation of and vigilance to prevent harms before they occur is surely a better strategy than attempting to contain or mitigate harms that have occurred.

\section{Conclusions}

New ICTs are being integrated throughout the humanitarian sector in areas as diverse as management practices, supply chain operations, and clinical care. Many of these applications 
use focused technologies to accomplish specific tasks such as water filtering or point of care testing; others incorporate sophisticated technologies with broader functions, such as GIS analysis of a disaster site. These developments are resulting in many improvements in how humanitarian medical assistance is provided to affected populations. However, they also require careful consideration of their political, social and ethical implications.

Humanitarian agencies need to manage increasingly large quantities of potentially sensitive data, provide rapid responses to unfolding crises, and weigh requests for access to their data, all the while ensuring that their data are reliable, data analysis is rigorous, confidentiality and privacy are respected, fairness is ensured, and risks are minimized. This is no small order. It has significant ethical implications as outlined in this paper, as well as operational and human resource implications as organizations increasingly need to develop new capacities and incorporate specialists with expertise in these areas. There have been calls and initiatives to establish clear ethical standards ${ }^{53}$ and to develop codes of ethics/conduct for new ICT applications (such as the code of conduct of the Standby Volunteer Task Force; and the Humanitarian UAV Code of Conduct and Guidelines). ${ }^{47,54}$

Technologies are contributing to the creation of new relationships between groups such as professional humanitarians and volunteer networks involved in crowdsourced live mapping, and with technology companies. In some settings, they are also reshaping relationships between humanitarian workers and local populations. Evaluating how the traditional humanitarian principles of neutrality, impartiality and independence can be upheld, along with consideration of other values such as fairness, presence and responsiveness, should be a focus of discussion within the humanitarian aid sector.

Humanitarian medical assistance unfolds within contexts that are highly volatile and contested. ICTs are not immune to these same adversities, but bring with them further complexities and vulnerabilities. Ethical consideration of novel ICTs in humanitarian aid embodies the dictum that 'can does not imply ought'; contemplation and vigilance are needed, including recognition that not all problems have technological solutions. ${ }^{55}$ The rapid advance of humanitarian ICTs raises important ethical questions. It is crucial that these questions be asked and that humanitarian medical organizations and others involved in humanitarian ICT innovation develop and implement new applications in ways that uphold humanitarian commitments, protect individuals and groups who are especially vulnerable, and minimize risks of harm. Thus while stifling or withholding potentially life-saving technologies is unethical, so too is their haphazard or hasty implementation.

Authors' contributions: $\mathrm{MH}$ and JP developed the first draft of the article. All authors contributed to analysis and interpretation, revised the manuscript; and read and approved the final version. $\mathrm{MH}$ is the guarantor of the paper.

Acknowledgements: The authors thank Cathy Tansey, Lynda RedwoodCampbell and Anant Bhan for their helpful insights regarding ICTs, ethics and humanitarian aid, and Jingru Miao for his work as a research assistant. Matthew Hunt is a Chercheur Boursier of the Fonds de Recherche du Québec-Santé and Lisa Schwartz is the Arnold L Johnson Chair in Health Care Ethics at McMaster University.

\section{Funding: None.}

Competing interests: None declared.

Ethical approval: Not required.

\section{References}

1 IEEE. Institute of Electrical and Electronics Engineers' Global Humanitarian Technology Conference: Technology for the Benefit of Humanity. http://www.ieeeghtc.org [accessed 26 April 2016].

2 IFRC. World Disasters Report 2013. Focus on technology and the future of humanitarian action. Geneva: The International Federation of Red Cross and Red Crescent Societies; 2013. http://www.ifrc.org/ wdr2013 [accessed 26 April 2016].

3 American Red Cross. A global dialogue on emerging technology for emerging needs. Wahington, DC: American Red Cross; 2016. http:// www.tech4resilience.org [accessed 3 May 2016].

4 Barbour V, Clark J, Simpson P et al. Digital humanitarianism: collective intelligence emerging. PLoS Med 2012;9:e1001278.

5 Meier P. Digital Humanitarians: How Big Data Is Changing the Face of Humanitarian Response. Boca Raton: CRC Press; 2014.

6 Bendor AP. In West Africa's Ebola Crisis, a Mobile Phone-Based Hero for Health Workers. Chapel Hill: IntraHealth International; 2014. http://www.intrahealth.org/blog/west-africa\%E2\%80\%99sebola-crisis-mobile-phone-based-hero-health-workers\#.VyprSmQrJcx [accessed 4 May 2016].

7 ITU. ICT Facts and Figures - The world in 2015. Geneva: International Telecommunication Union; 2015. http://www.itu.int/ en/ITU-D/Statistics/Pages/facts/default.aspx [accessed 26 April 2016].

8 Fornace KM, Drakeley CJ, William T et al. Mapping infectious disease landscapes: unmanned aerial vehicles and epidemiology. Trends Parasitol 2014;30:514-9.

9 Roche S, Propeck-Zimmermann E, Mericskay B. GeoWeb and crisis management: Issues and perspectives of volunteered geographic information. GeoJournal 2013;78:21-40.

10 ICRC. Mapping restoring family links in the Middle East and North Africa. Geneva: International Committee of the Red Cross and National Red Cross and Red Crescent Societies; 2015. http:// familylinks.icrc.org/en/Pages/NewsAndResources/News/RFL-MiddleEast-North-Africa-Map.aspx [accessed 26 April 2016].

11 Sandvik KB, Lohne K. The rise of the humanitarian drone: giving content to an emerging concept. Millenn J Int Stud 2014;43:145-64.

12 Hiltz SR, Van de Walle B, Turoff M. The Domain of Emergency Management Information. Information Systems for Emergency Management. New York: Routledge; 2011.

13 Salathé M, Bengtsson L, Bodnar TJ et al. Digital epidemiology. PLoS Comput Biol 2012;8:e1002616.

14 Syahriar A, Prihantoro E. Roles of Information and Communication Technology in Tsunami Early Warning Systems. e-Indonesia Initiative. 2008. http://iatt.kemenperin.go.id/tik/fullpaper/fullpaper121_Ary\% 20Syahriar_dan_Pariatmono.pdf [accessed 26 April 2016].

15 BBC Media Action. Still left in the dark? How people in emergencies use communication to survive - and how humanitarian agencies can help. London: BBC Media Action; 2012. http://www.bbc.co.uk/ 
mediaaction/publications-and-resources/policy/briefings/policy-stillleft-in-the-dark [accessed 26 April 2016].

16 Van de Walle B, Dugdale J. Information management and humanitarian relief coordination: findings from the Haiti earthquake response. Int J Bus Contin Risk Manage 2012;3:278-305.

17 Saab DJ, Maldonado E, Orendovici R et al. Building global bridges: Coordination bodies for improved information sharing among humanitarian relief agencies. Proceedings of the 5th International ISCRAM Conference. Washington DC; 2008. https://www.itu.int/en/ ITU-D/Emergency-Telecommunications/Documents/ET-OnlineToolkit/bp/ Coordination\%20Bodies\%20for\%20improved\%20information\%20 sharing\%20among\%20humanitarian\%20relief\%20agencies\%20-\%20 ISCRAM\%20Conference'08.pdf [accessed 3 May 2016].

18 Ergun Ö, Gui L, Heier Stamm JL et al. Improving humanitarian operations through technology-enabled collaboration. Prod Oper Manag 2014;23:1002-14.

19 Sifferlin A. The First Attempt to Digitize Ebola Health Records. New York: Time Inc; 2014. http://time.com/3615990/ebola-electronichealth-records [accessed 26 April 2016].

20 Wootton R, Geissbuhler A, Jethwani $K$ et al. Long-running telemedicine networks delivering humanitarian services: experience, performance and scientific output. Bull World Health Organ 2012;90: 341-7D.

21 Latifi R, Tilley EH. Telemedicine for disaster management: can it transform chaos into an organized, structured care from the distance? Am J Disaster Med 2013;9:25-37.

22 Cicero MX, Walsh B, Solad $Y$ et al. Do you see what I see? Insights from using Google Glass for disaster telemedicine triage. Prehosp Disaster Med 2015;30:4-8.

23 ICRC. New video game contest promotes respect for health-care personnel and facilities. Geneva: International Committee of the Red Cross; 2014. https://www.icrc.org/eng/resources/documents/ audiovisuals/video/2014/05-28-video-game-contest-health-care-indanger.htm [accessed 26 April 2016].

24 Kopczak L, Johnson ME. Rebuilding Confidence: Trust, Control and Information Technology in Humanitarian Supply Chains. Academy of Management Annual Meeting, August 3-8, Philadelphia PA; 2007. http://citeseerx.ist.psu.edu/viewdoc/download?doi=10.1.1.135.249\& rep=rep1\&type=pdf [accessed 26 April 2016].

25 de Waal A, Hazlett C, Davenport C, Kennedy J. The epidemiology of lethal violence in Darfur: Using micro-data to explore complex patterns of ongoing armed conflict. Soc Sci Med 2014;120:368-77.

26 Ensor C. Biometrics in aid and development: game-changer or trouble-maker? London: The Guardian 22 February 2016. http://www. theguardian.com/global-development-professionals-network/2016/ feb/22/biometrics-aid-development-panacea-technology [accessed 26 April 2016].

27 Agoada J. Can Drones and 3-D Printers Save Lives? Emerging Technology Choices in Humanitarian Response. New York: Huffington Post; 27 January 2015. http://www.huffingtonpost.com/josephagoada/can-drones-and-3d-printer_b_6526608.html. [accessed 26 April 2016].

28 Jones S. When disaster strikes, it's time to fly in the 3D printers. London: The Guardian 30 December 2015. http://www.theguardian. com/global-development/2015/dec/30/disaster-emergency-3d-printinghumanitarian-relief-nepal-earthquake [accessed 26 April 2016].

29 Sandvik KB, Jumbert MG, Karlsrud J, Kaufmann M. Humanitarian technology: a critical research agenda. Int Rev Red Cross 2014;96:219-42.

30 Ferris E. Megatrends and the future of humanitarian action. Int Rev Red Cross 2011;93;915-38.
31 Ward JS, Barker A. Undefined By Data: A Survey of Big Data Definitions. arXiv 2013;1309.5821v1[cs.DB]. http://arxiv.org/abs/ 1309.5821 [accessed 26 April 2016].

32 Searle L, Wynn-Pope P. Crisis Mapping, Humanitarian Principles and the application of Protection Standards - A dialogue between Crisis mappers and Operational Humanitarian Agencies. World Vision Meeting Record, Geneva, 17 November 2011. https://irevolution.files. wordpress.com/2012/02/world-vision-geneva-report.pdf [accessed 26 April 2016].

33 Greenough PG, Chan JL, Meier P et al. Applied technologies in humanitarian assistance: report of the 2009 Applied Technology Working Group. Prehos Disaster Med 2009;24:S206-9.

34 Donini A, Maxwell A. From face-to-face to face-to-screen: implications of remote management for the effectiveness and accountability of humanitarian action in insecure environments. Int Rev Red Cross 2013;95:383-413.

35 Eckenwiler L, Hunt M. Counterterrorism, ethics, and global health. Hastings Cent Rep 2014;44:12-3.

36 Morozov E. The Net Delusion: The Dark Side of Internet Freedom New York: PublicAffairs; 2011.

37 Schneier B. Data and Goliath: The Hidden Battles to Collect Your Data and Control Your World. New York: W.W. Norton \& Company; 2015.

38 Ashford W. Internal threat among biggest cyber security challenges, says former FBI investigator. Computer Weekly 29 June 2015. http:// www.computerweekly.com/news/4500248908/Internal-threat-amongbiggest-cyber-security-challenges-says-former-FBI-investigator [accessed 3 May 2016].

39 MSF. GIS Support for the MSF Ebola response in Guinea in 2014. Geneva: Médecins Sans Frontières; 2014. http://cartong.org/sites/ cartong/files/GIS\%20Support\%20for\%20the\%20MSF\%20Ebola\% 20Response\%20in\%20Guinea_Case\%20Study.pdf [accessed 26 April 2016].

40 Madianou M, Longboan L, Ong J. Finding a voice through humanitarian technologies? Communication technologies and participation in disaster recovery. Int J Commun 2015;9:3020-38.

41 Calain P. Ethics and images of suffering bodies in humanitarian medicine. Soc Sci Med 2013;98:278-85.

42 Lawlor DA, Stone, T. Public health and data protection: an inevitable collision or potential for a meeting of minds? Int Epidemiol 2001;30:1221-5.

43 Fox RC. Doctors without Borders: Humanitarian Quests, Impossible Dreams of Médecins Sans Frontières. Baltimore: Johns Hopkins University Press; 2014.

44 Collison A, Duffield M. Paradoxes of presence: Risk management and aid culture in challenging environments. London: Humanitarian Policy Group. 2013. http://www.odi.org/sites/odi.org.uk/files/odiassets/publications-opinion-files/8428.pdf [accessed 26 April 2016].

45 UN Foundation. Relief 2.0: The Future of Information Sharing in Humanitarian Emergencies. Washington DC: United Nations Foundation; 2011. http://www.unfoundation.org/news-and-media/ publications-and-speeches/disaster-relief-2-report.html [accessed 26 April 2016].

46 Lupton D. Critical perspectives on digital health technologies. Soc Compass 2014;8:1344-59.

47 Meier P. Humanitarian UAV Missions: Towards Best Practices. iRevolutions; 2015. http://irevolution.net/2015/06/01/humanitarianuav-missions-towards-best-practices [accessed 3 May 2016].

48 Friedman B, Kahn PH Jr., Borning A. Value sensitive design and information systems. In: Zhang P, Galletta D (editors). Human-Computer 
Interaction in Management Information Systems: Foundations. Armonk: M.E. Sharpe; 2006, p. 348-72.

49 Stahl BC, Heersmink R, Goujon P, Flick C. Issues, Concepts and Methods Relating to the Identification of the Ethics of Emerging ICTs. Communications of the IIMA 2010;10:33-43.

50 Duffield M. Disaster-Resilience in the Network Age Access-Denial and the Rise of Cyber-Humanitarianism. Copenhagen: Danish Institute for International Studies; 2013. DIIS Working Paper 2013:23.

51 Hunt MR, Schwartz L, Sinding C, Elit L. The ethics of engaged presence: a framework for health professionals in humanitarian assistance and development work. Dev World Bioeth 2014;14:47-55.
52 Winston ME. Children of Invention Revisited. In: Winston ME, Edelbach RD (editors). Society, Ethics and Technology. Belmont: Wadsworth, Cengage Learning; 2000, p. 1-26.

53 UN Office for the Coordination of Humanitarian Affairs. Humanitarianism in the Network Age. New York: United Nations Publication; 2013.

54 Standby Task Force. Our Code of Conduct. http://www. standbytaskforce.org/about-us/our-code-of-conduct [accessed 26 April 2016].

55 Morozov E. To save everything, click here: The folly of technological solutionism. New York: Public Affairs; 2014. 